\title{
Olhai os delírios do Campus ${ }^{1}$ \\ Look at the delusions of Campus
}

\author{
LARISA DA VEIGA VIEIRA BANDEIRA²
}

Este texto inicia em um convite para participar da XXII Semana Acadêmica de Filosofia - Filosofia e Literatura: pensando esse encontro, o convite disparou a escrita quando pensei em estar junto, em espaço de compartilhamento, de trocas e de encontro, onde os estudantes e professores escutam, apresentam, discutem os temas que são pertinentes a isso que vivemos. Esse texto inicia também com um agradecimento pela oportunidade de estar na Unioeste em tempo de sombras e sobras, no qual a possibilidade de estar junto já é prova de que estamos vivos, que permanecemos fortes e que, seja qual for o nome que queiram dar para o que fazemos, não aceitaremos nada que não nos reconheça como produtores de pesquisa, de ensino, de extensão, de afetos, de encontros e de vida. É de fato uma alegria estar aqui, lugar no qual vivenciei um dos encontros mais significativos do Projeto Escrileituras ${ }^{3}$ em um campus habitado pela vontade de experimentar.

Quando fui convidada para o encerramento do evento, pensei nas muitas horas de trabalho de todos que estiveram envolvidos na organização e na sua realização. No cansaço daqueles que apresentaram suas comunicações e passaram por momentos de ansiedade e alívio e também naqueles que precisam vir de cidades vizinhas. E na responsabilidade que é encerrar um evento organizado por um curso de Filosofia no dia de hoje, no dia 17 de maio de um ano como este que está sendo 2019. Quando foi solicitado o título da conferência demorei alguns dias para enviar, a escolha do título derivou de uma conversa com o Professor André Luiz Marenco dos

\footnotetext{
${ }^{1}$ Texto da palestra proferida no encerramento da XXII Semana Acadêmica de Filosofia - Filosofia e Literatura: pensando esse encontro, realizada no dia 17 de maio de 2019.

${ }^{2}$ Licenciada em Pedagogia pela Universidade Federal do Rio Grande do Sul (2008-2012). Mestrado em Educação pelo PPGEDu/UFRGS (2012-2014). Doutorado em Educação pelo PPGEDu/UFRGS (20152018). Experiência em formação continuada com professores da Educação Infantil, Anos Iniciais e Finais da Educação Básica, Ensino Médio e Educação de Jovens e Adultos na modalidade presencial e EAD. Coordenadora pedagógica no Colégio Marista Maria Imaculada Canela/RS. E-mail: lvvbandeira@gmail.com.

${ }^{3}$ Projeto Escrileituras: um modo de ler-escrever em meio à vida, do Observatório da Educação (OBEDUC- Edital 038 - 2010 - Coordenação de Aperfeiçoamento de Pessoal de Nível Superior (CAPES), Instituto Nacional de Estudos e Pesquisas Educacionais Anísio Teixeira (INEP) sob a orientação da Professora Dra. Sandra Mara Corazza (PPGEDU/UFRGS). O projeto foi desenvolvido em regime de colaboração entre quatro núcleos situados em Instituições de Ensino Superior: UFRGS - coordenado pela Profa. Dra. Sandra Mara Corazza; UFEPel - coordenado pela Profa Dra Carla Gonçalves Rodrigues; UFMT - coordenado pelo Prof. Dr. Silas Borges Monteiro e UNIOESTE Campus Toledo PR - coordenado pela Profa. Dra. Ester Maria Dreher Heuser e teve a execução das oficinas propostas, de forma sistemática, em escolas de educação básica. As ações desenvolvidas durante a vigência do Projeto resultaram em qualificada produção educacional, didático-pedagógicas, produções bibliográficas, teses e dissertações, cujo impactos das ações/atividades do projeto na: formação de professores; licenciaturas envolvidas; educação básica; pós-graduação e escolas participantes produziram desdobramentos institucionais.
} 
Santos, Professor Titular do Departamento de Ciência Política e do Programa de PósGraduação em Políticas Públicas da Universidade Federal do Rio Grande do Sul. Na ocasião o professor contou que participou do movimento estudantil em uma entidade de base fundada no início da década de 8o. Quando da implementação do Campus do Vale da UFRGS no final da década de 70, o então Instituto de Filosofia, Ciências Humanas e Letras foi instalado nos primeiros prédios construídos no local, no entorno da cidade, pretendia-se que tais cursos, ao saírem do Campus do centro, ficassem confinados e distantes e se tornassem inofensivos. Naquele momento, o espaço destinado à organização dos estudantes passou a abrigar um diretório uno, reunindo os alunos de todos os cursos da unidade, o DAIU (Diretório Acadêmico dos Institutos Unificado). Já nos idos de 1979, teve início uma discussão acerca da organização de centros acadêmicos por cursos. Porém, foi da articulação política desses jovens no DAIU que surgiu a ideia de um jornal, feito no mimeógrafo, de tiragem pequena, mas que desse conta do sonho coletivo que se instaurava ali. Que contasse um pouco da respiração própria e das dinâmicas desses estudantes de Filosofia, Ciências Humanas e Letras. O nome desse jornal era: Olhai os Delírios do Campus. Nele estavam os contos, as tirinhas, as notícias, as datas importantes, um pouco do tanto das vozes que pretendiam calar quando isolaram tais cursos no Campus do Vale.

Pensei ao dar o nome do jornal para a minha fala desta noite, em trazer um pouco dos estudantes de outros tempos, de tempos que eram chamados de "anos de chumbo". Parece que cada tempo tem um tom, uma cor, alguns tempos são monocromáticos, e é dada aos jovens e principalmente aos estudantes a responsabilidade de trazer outras cores a estes tempos.

O coletivo de autores do jornal: Olhai os Delírios do Campus queria mostrar que aquilo que deveria estar escondido, calado e invisível no Campus do Vale se mantinha operante e convicto, era real e queria ser visto. Aquele grupo de estudantes publicava de forma artesanal, em folhas empapadas de álcool que giravam em um mimeógrafo velho, aquilo que, para quem havia delimitado o espaço geográfico destes cursos nos confins da cidade, consideravam ser um delírio febril.

A conversa sobre o jornal acabou sem eu saber se o nome havia sido escolhido fazendo referência ao Romance de Érico Veríssimo: Olhai os Lírios dos Campos, escrito em 1938. No prefácio de uma das centenas de edições que este livro teve em 1966, Érico escreveu:

Com a publicação de Olhai os Lírios do Campo operou-se uma mudança considerável em minha vida. O romance obteve tão grande sucesso de livraria, que se esgotaram dele várias edições em poucos meses, deixando editores e escritor igualmente satisfeitos e perplexos. Tamanha foi a influência desse livro no espírito de certos leitores, que ele teve a força de arrastar consigo os romances que o autor publicara até então em tiragens modestas que levavam quase dois anos para se esgotarem. Posso afirmar que só depois do 
aparecimento de Olhai os Lírios do Campo é que pude fazer profissão da literatura (VERÍSSIMO, 1966. p. 4).

Ainda me pergunto se os estudantes de Filosofia, Letras e outras "humanas" do DAIU não se referiam diretamente ao trecho do evangelho de Mateus que, com certeza, serviu de título para a obra de Veríssimo. Trecho que aqui destaco:

E, quanto ao vestuário, por que andais solícitos? Olhai para os lírios do campo, como eles crescem; não trabalham nem fiam; E eu vos digo que nem mesmo Salomão, em toda a sua glória, se vestiu como qualquer deles. [...] Não vos inquieteis, pois, pelo dia de amanhã, porque o dia de amanhã cuidará de si mesmo. Basta a cada dia o seu mal (Mateus, 6:25-34).

Qual o mal de nosso dia? Quanto do mal de nosso dia nos basta?

Dado o título da palestra, ainda no mês de março, iniciei um texto que ficou sempre em construção, como falar sobre isso que é considerado delírio febril de jovens inquietos nos campus de hoje?

Como falar do que é delirante, quando não basta apenas construir campus em espaços mais distantes do centro da cidade, mas é mais fácil e mais rápido silenciar tais cursos no seu apagamento dos currículos das escolas, na base nacional comum curricular, ou simplesmente dizer que: "Não é adequado usar dinheiro público em tais cursos, o ideal é direcionar esses investimentos a cursos mais sérios, por exemplo, medicina ou engenharia."

Ou o que dizer de um tempo marcado por uma sucessão de fatos arbitrários e insensatos desprovidos de sentido?

Ainda em março, envolvida com as questões que são comuns ao início do ano letivo em uma escola com 450 estudantes de anos finais e ensino médio, procurava com urgência um professor de filosofia, acreditem eles são raros e muito difíceis de achar, e muitas vezes, ainda hoje, quem ocupa esse lugar é o professor com licenciatura em geografia ou história. Principalmente em cidades pequenas do interior. Além de raros, os professores de filosofia têm uma carga horária pequena, e algumas vezes restrita ao ensino médio. O que torna ainda mais difícil encontra-los nas cidades pequenas. Já em desespero, na segunda quinzena de março consegui contratar um professor de filosofia, com mestrado e que percorre 320 quilômetros por semana para fechar a carga horária de 40 horas lecionando em três cidades próximas.

O campo curricular é um campo de batalha de forças econômicas, mais do que políticas, subtrair a Filosofia, assim como a Sociologia e a Arte do currículo é um risco que corremos todos os dias. Em uma das reuniões pedagógicas que acontecem na escola todas as semanas solicitei para cada um dos professores de cada uma das áreas do conhecimento, que fizessem um exercício para tentar convencer os colegas 
da importância de seu componente curricular permanecer. No exercício de tentar convencer os colegas, os professores produziriam os argumentos que consideravam pertinentes e importantes, apresentariam os argumentos que convenceriam os colegas a lutar com ele uma luta comum, para garantir o acesso e a permanência do conhecimento de seu componente curricular.

Tática de guerrilha na reunião pedagógica, usada na tentativa de construir as condições para a criação conjunta de enfrentamento da imprevisibilidade e a rapidez das decisões estapafúrdias, tomadas dia após dia por um desgoverno em seu plano de desmonte e desajustes na educação. Além das tantas outras questões enfrentadas em sala de aula como a troca do sofrimento pela dor pelos adolescentes, expressada em mutilações e tentativas de suicídio ou a crescente desmotivação dos estudantes pelos assuntos acadêmicos, não apenas de desempenho, mas o mais preocupante: a desmotivação pelo aprender e pelas interações sociais na escola, substituídas pelas relações virtuais. Em meio a isso e a tantas outras coisas que aqui escapam, sugeri aos professores que fizessem uma defesa de seus componentes curriculares, na esperança que eles conseguissem produzir vias conjuntas de defesa.

Trouxe aqui um trecho do argumento utilizado pelo colega de vocês, professor de filosofia Rafael Alves de Oliveira, viajante dos 320 quilômetros semanais em seu fusca branco, que tem a carga horária e o sustento equilibrado em três diferentes municípios:

Não se apeguem a definição de filosofia como amor a sabedoria. Isso é seu nome e filosofia é mais que um nome. Guardem no coração a definição de filosofia do professor da Universidade Federal Fluminense, Claudio Ulpiano, já falecido: filosofia é uma máquina de guerra instalada no campo social, e por isso, filosofia é coisa séria. Ela mata, protege e salva. Filosofia nos permite criar uma nova subjetividade, ela dá condições para que se manifeste todo o potencial revolucionário de novos desejos, de novas vidas. Aprendam a operar esta máquina com cuidado e façam da tolice algo vergonhoso. Lutem e lutem porque vivemos tempos duros e precisamos de filósofos como poucas vezes precisamos em nossa história (OLIVEIRA, 2019).

Este é um tempo exigente, no qual precisamos inventar outros modos de estar juntos. De olhar para o outro, cuidando para que não nos tornemos reativos a tudo e a todos, pois dessa forma eles teriam vencido, enfraquecer-nos é o objetivo desses tempos, enfraquecer-nos para que não tenhamos mais vontade de estar juntos.

Escutar o outro para que possamos juntos produzir. Coletivamente produzir, como os estudantes do Campus do Vale nos idos da década de 1980. Escutar, ler e escrever juntos, talvez um jornalzinho barato e etílico, para contar o que fazemos nos Campus das universidades públicas brasileiras, delírios inimagináveis para aqueles que pensam que nossa vida se resume em balbúrdia. 
Ler, escutar e escrever. Proponho também a vocês no pensar o possível encontro da Filosofia com a Literatura, exercícios de escritas que seriam compartilhadas coletivamente, não apenas nas semanas acadêmicas, mas nos corredores da universidade, no transporte coletivo, na cantina e no bar, a escrita desmedida, a escrita descolada dos trabalhos acadêmicos. A escrita sem medo da nota e da correção, mas ocupada na defesa da vida coletiva.

Escrevam de modo laboral, usando o lápis e a caneta, escrevam sem medo, não digitem, escrevam, não resumam, não abreviem, coloquem as palavras no papel.

Escrever faz arder o corpo, para percebermos que mesmo embebidos e enfaixados nos líquidos e tecidos da morte, ainda estamos tão mais vivos do que jamais estivemos. Escrevam em fragmentos, em guardanapos de papel, no espelho do banheiro embaçado pelo vapor do chuveiro. Será um exercício claudicante.

Para escrever, primeiro a mão deve encontrar uma brecha, no peito. Não se trata de uma questão de tempo. A escrita encontra seu tempo, tem seu ponto de ebulição, que pode acontecer no meio da agenda atribulada que inventamos para não escrever. É aquela lança que tentamos segurar enquanto está em movimento e que perfura a palma de nossa mão. O sangue é o que deixamos escorrer na página em branco. Então escrevemos.

Fiz uma pequena proposta de exercícios de escrita, para que possamos fazer aqui, mesmo que rapidamente, para aqueles que estejam dispostos a compartilhar, um parágrafo, uma frase, se alguém se sentir à vontade, no final, quando compartilhar, diga apenas a qual exercício seu fragmento corresponde, ou se inventou outra modalidade de exercício.

\section{Exercício 1}

Escrita pedrada: juntamos pequenos seixos, algumas pedras do leito do rio, guardamos nos bolsos de nossas roupas de crianças. Com elas tentamos algumas construções que levam tempo enorme em tentativas de equilibrar os pesos e a força, em tentativas de acertar a face de cada pedra de modo que outras pedras possam tomar acento. Com essa escrita podemos tentar usar algumas ferramentas, a indicação é o estilingue. Por se tratar de uma escrita que vem com os resquícios de infâncias é uma escrita que, ao ser utilizada com o estilingue, quebrará vidros, atravessará os espaços sem convites, incomodará os vizinhos. Esperamos apenas que essa escrita erre os passarinhos e as casas de abelhas.

\section{Exercício 2}

Escrita floco de neve: pequenas leituras do cotidiano, a poesia no ônibus, o grafite na rua, a orelha do livro que lemos de pé na livraria, o cartaz dos nossos alunos no corredor da escola, a tatuagem na pele e a pele do rapaz que está na fila 
do banco, a letra da música que insistimos em ouvir, flocos finos, singulares, únicos, delicados, porém afiados. Eles se acumulam e formam uma grossa camada de gelo sobre nós, se conseguirmos nos mover sob o peso e a pressão que nos causam, podemos remover com uma pá no final do dia. A ferramenta para a escrita floco de neve é a pá, que remove em quantidade sem quebrar a estrutura. Os flocos aparecem no texto, ainda brilhantes e afiados.

\section{Exercício 3}

Escrita cisco no olho: distração, solidão, saudades, angústia, pontinha de esperança. Tudo que irrita e coça o olho daquele que escreve, tudo que exige pequenas gotas de colírio, exige que pare de escrever para voltar a escrever. É aquilo que pede que o outro olhe dentro de nosso olho para ver se ele também consegue ver o que nos incomoda. Geralmente o nosso incômodo é invisível a olho nu. Por isso, a melhor ferramenta para essa escrita é o tapa-olho. Assim, o cisco perde a importância e, com isso, ganha o olho que ganha visibilidade ao ser escondido.

\section{Exercício 4}

Escrita tropeços e arrancadas: junte prazos, bibliografia, notas de rodapé, vinho, cerveja, postits, marcadores de página e marca texto, tesoura, navalhas e estilete para marcar a pele dos pés que insistem em andar no texto procurando pequenos trechos dos outros que escrevem para fixarem-se e sentirem-se seguros. A ferramenta para essa escrita é a joelheira, aquelas que eram cerzidas em nossas calças quando insistíamos em cair a cada passo dado. Com fortes joelheiras poderemos tropeçar e arrancar insistentemente. Até aprender a escrever nos desvios, nos atalhos, nos caminhos circulares, nas estradas vicinais.

A escrita arde, no meio desses dias sombrios. Escrevam filósofos, escrevam professores, escrevam estudantes, nossas palavras ganharão a folha de papel, o asfalto das ruas, o barro vermelho dos campos do Paraná, os ouvidos cansados e solitários, os que pensam que ante tantas situações que nos violentam todos os dias, não teremos mais a força de estar juntos.

Finalizo o texto agradecendo mais uma vez o convite, o encontro, a escuta e o estar junto.

São as alegrias que são oferecidas em doses generosas em encontros como este que nos fazem prosseguir, oscilando, nas pontes que criamos em esforço coletivo, para nos aproximar e constatar, que estamos todos tentando nos manter nos embates e na prática cotidiana da sobrevivência.

\section{Referências}

OLIVEIRA, R. A. "Intervenção", in XXII Semana Acadêmica de Filosofia - Filosofia e Literatura: pensando esse encontro, realizada no dia 17 de maio de 2019. 
VERÍSSIMO, Érico. Olhai os lírios do campo. 24. ed. Porto Alegre: Globo, 1966.

VVAA. Bíblia sagrada. Tradução de Padre Antônio Pereira de Figueredo. Rio de Janeiro: Encyclopaedia Britannica, 1980. Edição Ecumênica.

ZALLA, J. "Utopia e Paixão": sociabilidades estudantis e militância política na constituição do Centro Acadêmico de História da UFRGS - CHIST (1984-1987) in História Agora - A Revista de História do Tempo Presente, disponível em:

<http://www.educadores.diaadia.pr.gov.br/arquivos/File/2010/artigos_teses/2010/Historia/a rtigos/3zalla_artigo.pdf $>$.

Submissão: 24.05.2019 / Aceite: 30.05.2019. 